\title{
Analisis Sentimen Dan Topic Modelling Dalam Aplikasi Ruangguru
}

\author{
Muhammad Romy Firdaus ${ }^{1}$, Fikri Muhammad Rizki², Favian Muhammad Gaus ${ }^{3}$, Indra \\ Kusumajati Susanto ${ }^{4}$ \\ 1,2,3,4 Prodi S1 MBTI, Fakultas Ekonomi dan Bisnis, Universitas Telkom \\ Jl. Telekomunikasi Jl. Terusan Buah Batu, Sukapura, Kec. Dayeuhkolot, Bandung, Jawa Barat \\ romyfirdaus@student.telkomuniversity.ac.id ${ }^{1}$, fikrimrizki@student.telkomuniversity.ac.id ${ }^{2}$, \\ favianMGaus@student.telkomuniversity.ac.id ${ }^{3}$,indrakusumajati@student.telkomuniversity.ac.id4
}

\begin{abstract}
This study aims to determine and analyze responses regarding customer satisfaction Ruangguru Application to the learning space features in the Ruangguru Application at every level of education. This is useful to know the strengths and weaknesses of the Ruangguru Application based on sentiment responses from Ruangguru users. Ruangguru is an online tutoring startup and a technology-based educational content service and provider no. 1 in Indonesia. So of course, customer satisfaction is an important thing that is the goal of the company. So that when customer satisfaction is met, that is where the company can realize their goals. To see how the level of customer satisfaction, sentiment analysis methods and topic modeling are used in processing the data so that responses can be seen as to what is provided by the customer so that it can be an evaluation for the Ruangguru Application.
\end{abstract}

Keywords: Ruangguru Application, Sentiment Analysis, Topic Modeling, Customer Satisfaction, Education Level.

\begin{abstract}
Abstrak
Penelitian ini bertujuan untuk mengetahui dan menganalisis tanggapan mengenai kepuasan pelanggan Aplikasi Ruangguru terhadap fitur ruangbelajar dalam Aplikasi Ruangguru pada setiap jenjang pendidikan. Hal ini berguna untuk mengetahui kekuatan dan kelemahan dari Aplikasi Ruangguru berdasarkan respon sentimen dari pengguna Ruangguru. Ruangguru merupakan startup bimbel online serta penyedia layanan dan konten pendidikan berbasis teknologi no. 1 di Indonesia. Maka dari hal tersebut tentunya kepuasan pelanggan merupakan hal penting yang menjadi tujuan dari perusahaan. Sehingga saat kepuasan pelanggan terpenuhi, maka disitulah perusahaan dapat merealisasikan tujuan mereka. Untuk melihat bagaimana tingkat kepuasan dari pelanggan, digunakan metode analisis sentimen dan juga topic modelling dalam pengolahan datanya agar dapat dilihat respon seperti apa yang diberikan oleh pelanggan sehingga dapat menjadi evaluasi bagi Aplikasi Ruangguru.
\end{abstract}

Kata kunci: Aplikasi Ruangguru, Analisis Sentimen, Topic Modelling, Kepuasan Pelanggan, Jenjang Pendidikan.

\section{PENDAHULUAN.}

Di zaman sekarang, kemajuan teknologi sangat berpengaruh bagi kehidupan masyarakat, salah satu kemajuan teknologinya adalah di bidang pendidikan di mana sedang marak-maraknya aplikasi belajar online yang muncul di Indonesia, seperti aplikasi Ruangguru, Quipper, Zenius, dll,, di mana para penggunanya dari Ruangguru memiliki 15 Juta pengguna [12], Quipper memiliki 6 Juta pengguna [11], dan Zenius 11 Juta pengguna [10]. Ruangguru sebagai salah satu startup teknologi pendidikan terbesar di Indonesia dan telah dinobatkan menjadi penerima beragam penghargaan 
dari Google Developers, Unicef, Bubu Awards, MIT Solve, Atlassian Foundation, Department of Foreign Affairs and Trade Australia, KINSES, dan Rice Bowl, dan juga di tahun 2019 Ruangguru semakin booming di Indonesia, dimana hampir di setiap Televisi menyiarkan promosi Ruangguru, maka dari itu kami ingin meneliti bagaimana respon-respon mengenai Ruangguru [9].

Berdiri pada tahun 2014, Ruangguru merupakan perusahaan teknologi terbesar dan terlengkap di Indonesia yang berfokus pada layanan berbasis pendidikan dan telah memiliki lebih dari 6 juta pengguna serta telah mengelola lebih dari 150.000 guru yang menawarkan jasa di lebih dari 100 bidang pelajaran. Perusahaan ini didirikan sejak tahun 2014 oleh Belva Devara dan Iman Usman, yang keduanya berhasil masuk dalam jajaran pengusaha sukses dibawah 30 tahun melalui Forbes 30 under 30 untuk teknologi konsumen di Asia [9]. Ruangguru berkomitmen untuk menjadi mitra bagi pemerintah daerah demi memberikan pendidikan berkualitas melalui Sistem Manajemen Belajar (LMS). Tahun lalu, Ruangguru berhasil bekerja sama dengan 32 (dari 34) pemerintah provinsi dan lebih dari 326 pemerintah kota dan kabupaten di Indonesia. Selain itu, Ruangguru juga menawarkan video belajar berlangganan, marketplace les privat, layanan bimbingan belajar on-demand, tryout ujian online, dan lain-lain [9]. Ruangguru bukan hanya hadir sebagai sebuah bisnis, tetapi juga bertujuan untuk meningkatkan kualitas guru dengan menciptakan lapangan pekerjaan dan tambahan penghasilan bagi guru di Indonesia. Ruangguru percaya, dengan meningkatnya kualitas guru, maka mutu pendidikan di Indonesia juga akan menjadi lebih baik [9]. Ruangguru juga percaya bahwa teknologi dapat membantu siswa, guru, dan orang tua untuk menjalankan aktivitasnya menjadi lebih efektif dan efisien. Untuk itu, kami bertekad untuk terus mengembangkan layanan-layanan lainnya serta berkolaborasi dengan berbagai pihak guna mencapai tujuan ini [9].

Respon kepuasan pelanggan terhadap produk adalah faktor yang bisa digunakan untuk Ruangguru agar dapat menilai bagaimana dalam menentukan tujuan perusahaan sekaligus juga agar dapat melihat kinerja dari produk. Menurut Kotler \& Keller pengertian kepuasan pelanggan adalah tingkat keadaan perasaan seseorang yang merupakan hasil perbandingan antara penilaian kinerja/hasil akhir produk dalam hubungannya dengan harapan pelanggan [4]. Dapat disimpulkan kepuasan pelanggan adalah evaluasi pasca pemakaian produk. Kepuasan pelanggan mewakili suatu fokus strategi terpusat untuk perusahaan yang berorientasi pelanggan diberbagai industri. Sentimen dari komentar yang diberikan pelanggan terhadap suatu produk dapat mencerminkan seberapa puasnya pelanggan terhadap produk tersebut. Sehingga dapat diketahui seberapa besar kepuasan pelanggan setelah atau selama menggunakan produk tersebut. 


\section{METODOLOGI PENELITIAN}

\subsection{Kajian Literasi}

\subsubsection{Sentiment Analysis}

Sentiment adalah informasi tekstual yang berada di dalam web dan berisi tentang fakta dan opini. Sentiment merupakan pernyataan subjektif yang mencerminkan persepsi seseorang terhadap suatu peristiwa (Dave, Lawrence, \& Pennock, 2003) [1]. Penelitian lain menyatakan sentiment analysis adalah studi komputasi yang berhubungan dengan pendapat dan berorientasi dengan pengolahan bahasa alami (Kumar \& Sebastian, 2012)[2]. Secara umum, Sentiment analysis ini dibagi menjadi 2 kategori umum (Schneider, 2005) [3] :

a. Coarse-grained sentiment analysis

b. Fined-grained sentiment analysis

Coarse-grained sentiment analysis - kategori ini melakukan proses analisis pada level dokumen. Singkatnya adalah kita mencoba mengklasifikasikan orientasi sebuah dokumen secara keseluruhan. Orientasi ini ada 3 kategori : Positif, Netral, Negatif. Akan tetapi, ada juga yang menjadikan nilai orientasi ini bersifat kontinu atau tidak diskrit. Finedgrained sentiment analysis - kategori kedua ini yang sedang populer sekarang. Maksudnya adalah para peneliti sebagian besar fokus pada jenis ini. Obyek yang ingin diklasifikasi bukan berada pada level dokumen melainkan sebuah kalimat pada suatu dokumen.

\subsubsection{Kepuasan Pelanggan}

Menurut Kotler (2002) kepuasan pelanggan adalah perasaan senang atau kecewa seseorang yang muncul setelah membandingkan antara persepsi atau kesannya terhadap kinerja berada di bawah harapan, pelanggan tidak puas [4]. Tapi, jika kinerja melebihi harapan, pelanggan amat puas dan senang. Jika kinerja yang dirasakan di bawah harapan, pelanggan tersebut akan merasa dikecewakan, jika kinerja memenuhi harapan pelanggan, pelanggan akan merasa puas, sedangkan jika kinerja melebihi harapan maka pelanggan akan merasa sangat puas. Kepuasan ini tentu akan dapat dirasakan setelah pelanggan yang bersangkutan mengkonsumsi produk tersebut.

\subsubsection{Data}

Data berasal dari kata "Datum" yang berarti fakta atau bagian dari fakta yang mengandung arti yang dihubungkan dengan kenyataan yang dapat digambarkan dengan simbol, angka, huruf dan sebagainya. Atau dapat dikatakan data adalah merupakan fakta atau bagian dari fakta yang belum tersusun yang mempunyai arti yang dihubungkan dengan kenyataan yang benar-benar terjadi, fakta dapat dinyatakan dengan gambar (grafik), katakata, angka, huruf dan lain sebagainya. 


\subsubsection{Topic Modelling}

Konsep topic modelling menurut Blei terdiri dari entitasentitas yaitu "kata", "dokumen", dan "corpora". "Kata" dianggap sebagai unit dasar dari data diskrit dalam dokumen, didefinisikan sebagai item dari kosa kata yang diberi indeks untuk setiap kata unik pada dokumen. "Dokumen" adalah susunan N kata-kata. Sebuah corpus adalah kumpulan M dokumen dan corpora merupakan bentuk jamak dari corpus. Sementara "topic" adalah distribusi dari beberapa kosakata yang bersifat tetap. Secara sederhana, setiap dokumen dalam corpus mengandung proporsi tersendiri dari topiktopik yang dibahas sesuai kata-kata yang terkandung di dalamnya [5]. Ide dasar dari Topic Modelling adalah bahwa sebuah topik terdiri dari kata-kata tertentu yang menyusun topik tersebut, dan dalam satu dokumen memiliki kemungkinan terdiri dari beberapa topik dengan peluang masing-masing. Namun secara pemahaman manusia, dokumen-dokumen merupakan objek yang dapat diamati, sedangkan topik, distribusi topik per-dokumen, dan penggolongan setiap kata pada topik perdokumen merupakan struktur tersembunyi, maka dari itu topic modelling bertujuan untuk menemukan topik dan katakata yang terdapat pada topik tersebut [6].

\subsubsection{Jenjang Pendidikan}

Menurut Andrew E. Sikula dalam Mangkunegara tingkat pendidikan adalah suatu proses jangka panjang yang menggunakan prosedur sistematis dan terorganisir, yang mana tenaga kerja manajerial mempelajari pengetahuan konseptual dan teoritis untuk tujuan-tujuan umum [7]. Dengan demikian Hariandja menyatakan bahwa tingkat pendidikan seorang karyawan dapat meningkatkan daya saing perusahaan dan memperbaiki kinerja perusahaan.

Menurut UU RI No. 20 Tahun 2003 pasal 1, pada dasarnya jenjang pendidikan adalah tahapan pendidikan yang ditetapkan berdasarkan tingkat perkembangan peserta didik, tujuan yang akan dicapai, dan kemampuan yang dikembangkan [8]. Pendidikan adalah aktivitas dan usaha untuk meningkatkan kepribadian dengan jalan membina potensi-potensi pribadinya, yaitu rokhani (pikir, cipta, rasa, dan hati nurani) serta jasmani (panca indera dan keterampilan-keterampilan).

\subsection{Metode Penelitian}

Pada kegiatan ini metode yang digunakan adalah Sentiment Analysis. Kegiatan ini meneliti respon konsumen yang menggunakan fitur ruangbelajar dari Ruangguru melalui komentar yang ada di situs YouTube yang dilihat di berbagai Jenjang Pendidikan (SD, SMP, SMA) sehingga bisa didapatkan Sentimen dari komentar pelanggan yang ada di YouTube sehingga dapat diketahui bagaimana respon konsumen menggunakan fitur ruangbelajar dari Ruangguru. 


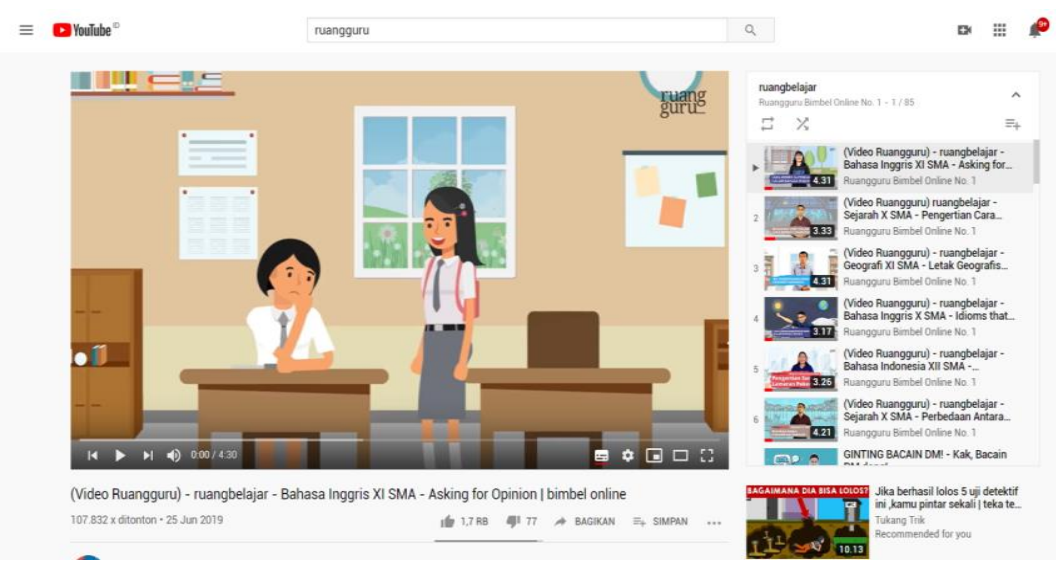

Gambar 1. Video Ruangguru yang termuat pada situs YouTube.com

\subsection{Sumber Data}

Data yang didapatkan adalah sebanyak 2.287 komentar. Data diambil dari website YouTube.com dengan video-video ruangbelajar yang berbeda di setiap jenjang pendidikan. Lalu setelah data dicleaning didapatkan 412 komentar. Data komentar tersebut kami ambil dengan rentang waktu 3 minggu. Yang dimulai pada tanggal 4 November 2019 hingga tanggal 25 November 2019.

\subsection{Teknik dan Alat Pengumpulan Data}

Teknik pengumpulan data dilakukan dengan cara scraping dan kami mengunakan aplikasi ScrapeStorm untuk memudahkan kami mendapatkan data yang valid dan akurat sehingga tidak ada data yang rusak, dan kami menganalisis/data dengan menggunakan aplikasi Orange. Alat yang digunakan untuk mengumpulkan dan menganalisis data adalah sebuah laptop.

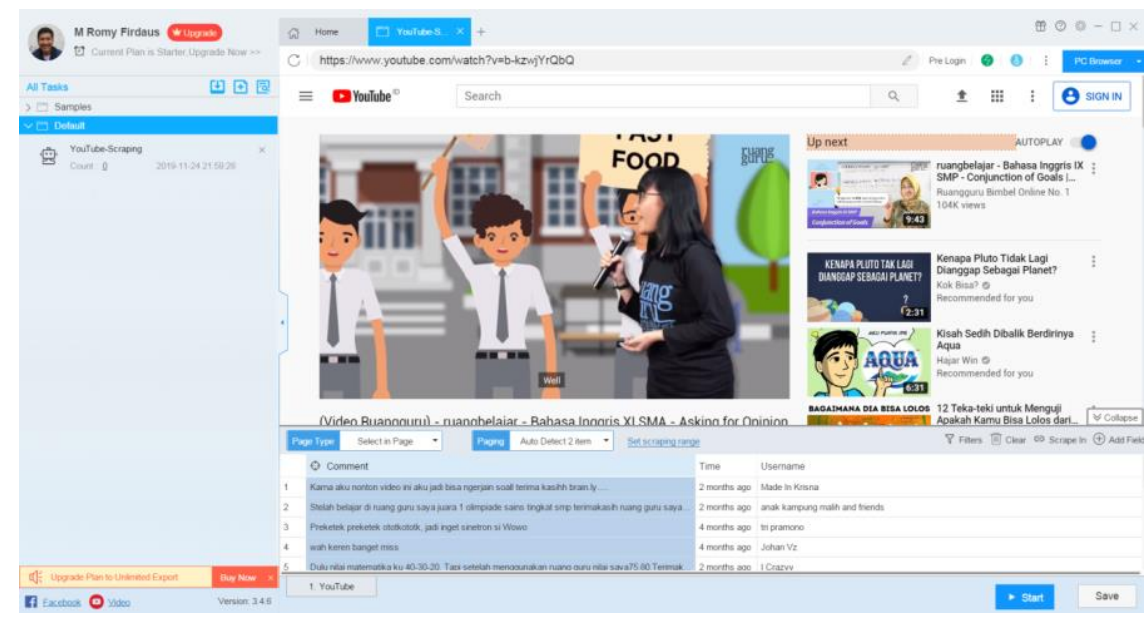

Gambar 2. Tools pengambilan data menggunakan Scrapestrom 


\section{HASIL DAN PEMBAHASAN}

Berdasarkan hasil data yang didapatkan, sampel diolah untuk pengambilan kesimpulan dan pembahasan. Data sampel berisikan sentimen yang diberikan oleh konsumen. Kemudian diklasifikasikan kedalam beberapa jenjang pendidikan untuk melihat kecenderungan kepuasan pemakaian fitur ruangbelajar dari Ruangguru berasal dari kelas mana. Berikut adalah hasil dari 412 data sampel yang telah diambil dari website YouTube.

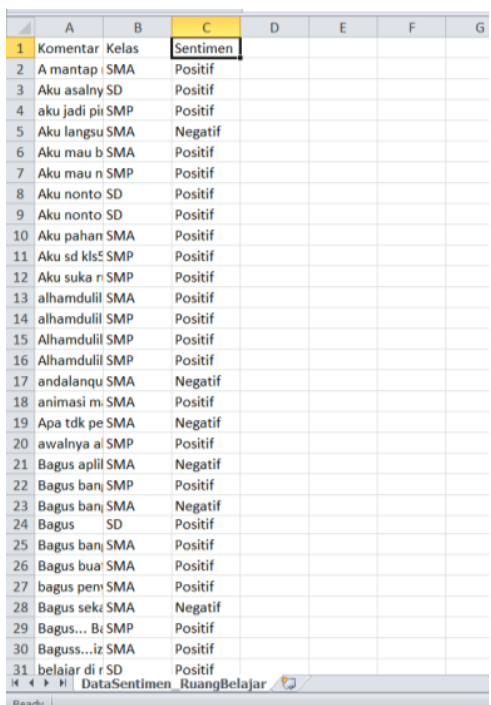

Gambar 3. Data training yang telah diberikan label

Komentar yang didapat dari hasil scrapping data, dicleaning terlebih dahulu lalu diberikan label sentimen positif atau negatif untuk setiap komentarnya, setelah itu komentar diklasifikasikan berdasarkan jenjang usia.

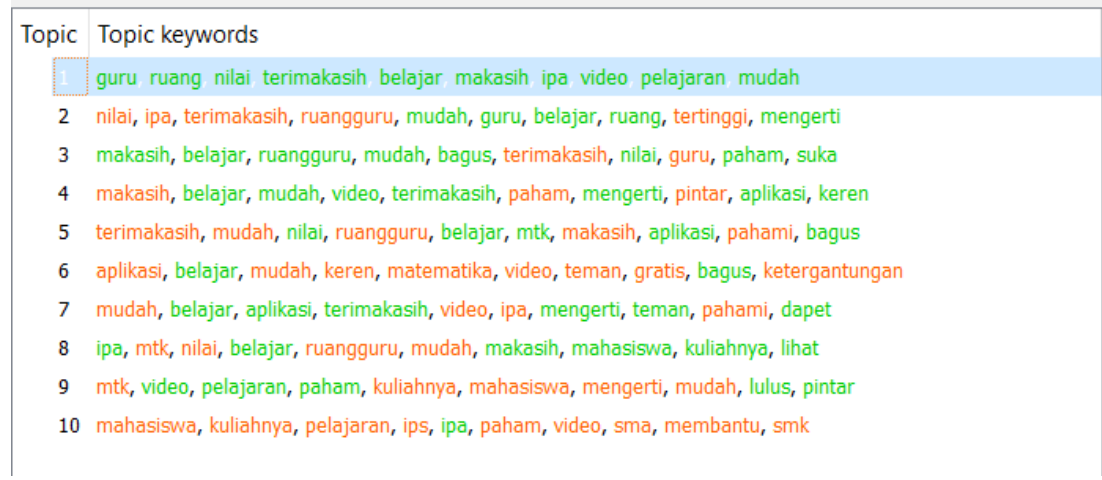

Gambar 4. Topic Modelling tanggapan pelanggan Ruangguru

Setelah itu, data hasil cleaning diolah menggunakan topic modelling di aplikasi Orange untuk mengidentifikasi topik-topik yang dibicarakan oleh pengguna di komentar YouTube Ruangguru mengenai respon terhadap fitur video ruangbelajar. 


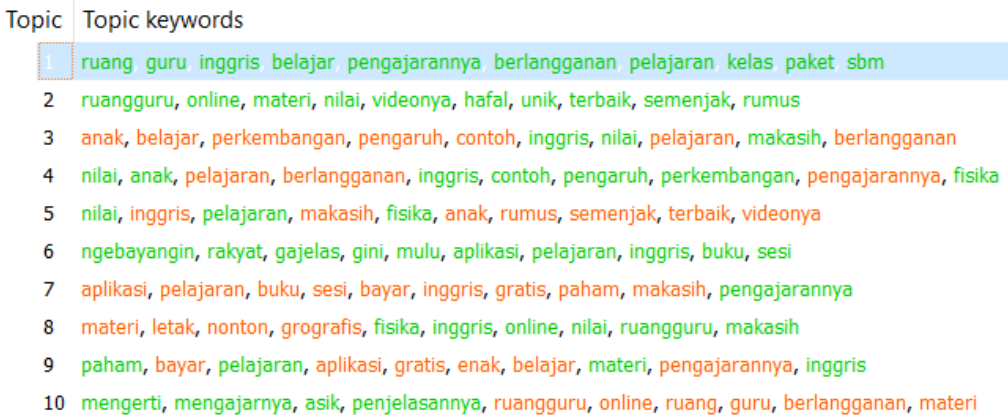

Gambar 5. Topic Modelling tanggapan positif pelanggan Ruangguru

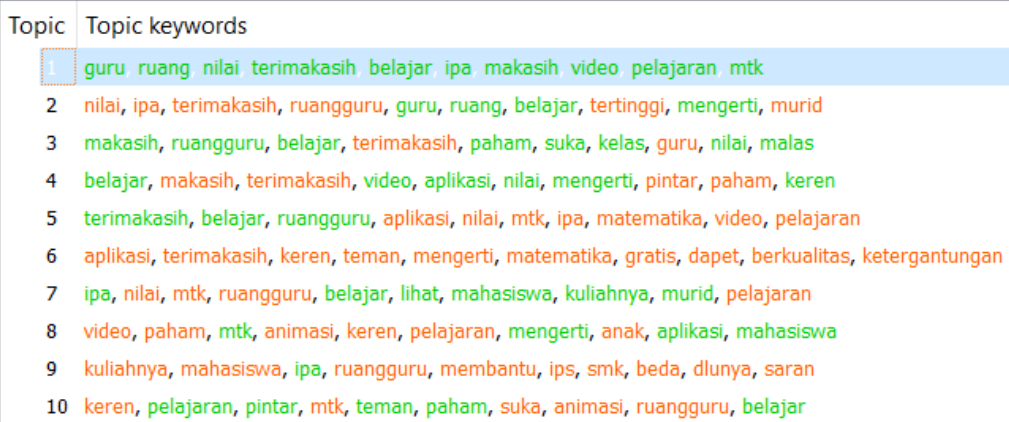

Gambar 6. Topic Modelling tanggapan negatif pelanggan Ruangguru

Untuk lebih spesifik dalam mengidentifikasi topik-topik apa saja yang dibicarakan oleh pengguna di komenar YouTube, kami membagi Topic Modelling menjadi dua berdasarkan sentimennya, yaitu berdasarkan sentimen negatif dan positif, dimana topik yang paling banyak dibicarakan di sentimen negatif adalah mengenai; belajar, pengajarannya, contoh, penjelasannya, dll, sedangkan di sentimen positif topik yang paling banyak dibicarakan adalah mengenai; nilai, terimakasih, belajar, video, dll.

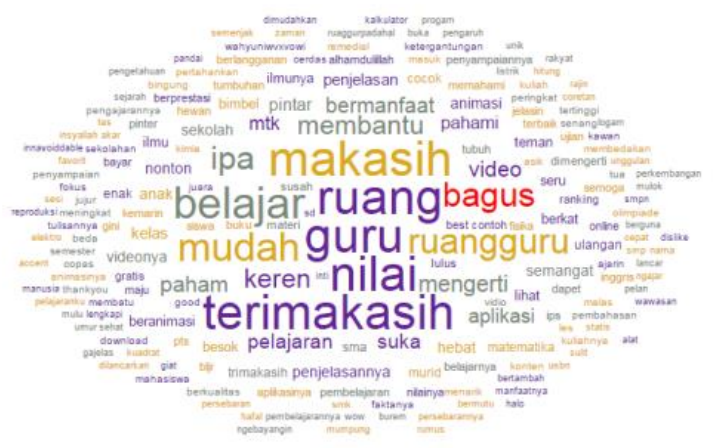

Gambar 7. Word cloud Ruangguru 
Setelah itu, data hasil cleaning diolah lagi menggunakan word cloud di aplikasi Orange untuk untuk mengidentifikasi kata-kata yang dibicarakan oleh pengguna di komentar YouTube Ruangguru mengenai respon terhadap fitur video ruangbelajar. Untuk lebih spesifik dalam mengidentifikasi katakata apa saja yang dibicarakan oleh pengguna di komenar YouTube, kami membagi word cloud menjadi dua berdasarkan sentimennya, yaitu berdasarkan sentimen negatif dan positif, dimana kata yang paling banyak muncul di sentimen negatif adalah kata; penjelasannya, paham, bayar, tulisan, aplikasi, buram, dll, sedangkan di sentimen positif kata yang paling banyak muncul adalah kata; nilai, terimakasih, belajar, keren, membantu, mengerti, dll.

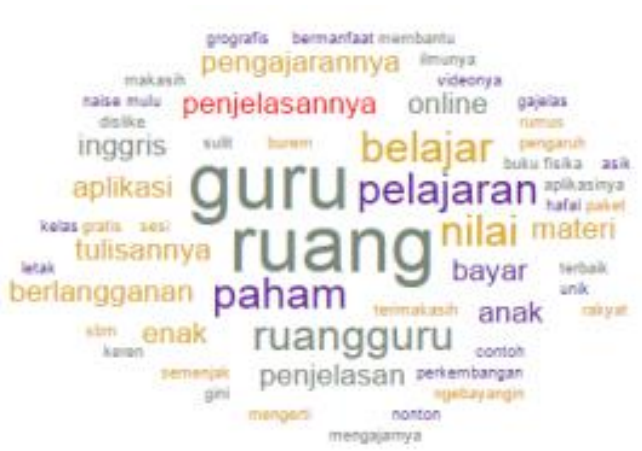

Gambar 8. Word cloud negatif pelanggan Ruangguru

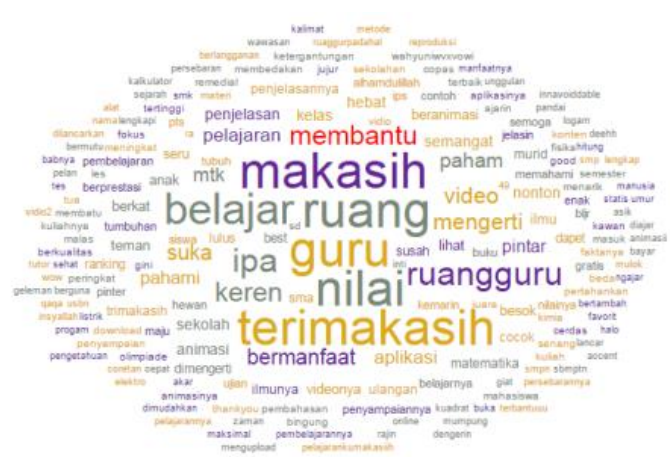

Gambar 9. Word cloud positif pelanggan Ruangguru

Selain itu, kami juga membagi pengolahan data menggunakan topic modelling dan word cloud berdasarkan jenjang pendidikan untuk melihat topik-topik yang paling sering dibicarakan dan kata-kata yang paling sering muncul di jenjang pendidikan tertentu.

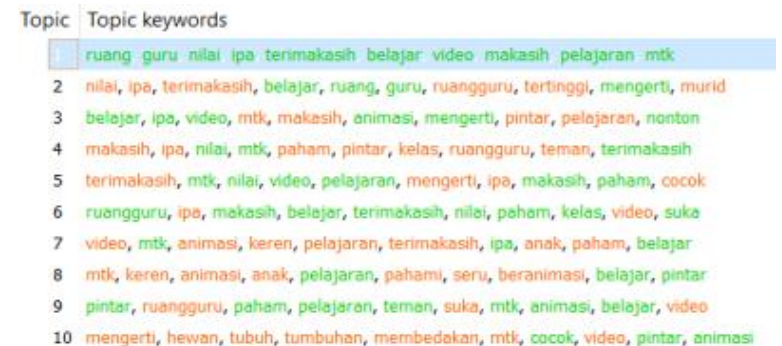

Gambar 10. Topic Modelling jenjang pendidikan SMA

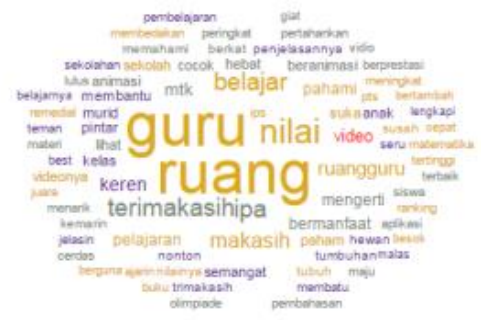

Gambar 11. Word cloud jenjang pendidikan SMA

Di jenjang SMA, topik yang paling banyak dibicarakan adalah mengenai; nilai, terimakasih, belajar, video, dll, dan kata yang paling banyak muncul adalah kata; nilai, ipa, terimakasih, belajar, keren, mtk, dll. 


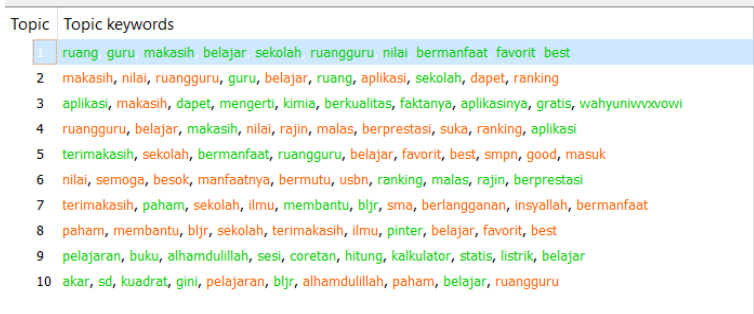

Gambar 12. Topic Modelling jenjang pendidikan SMP

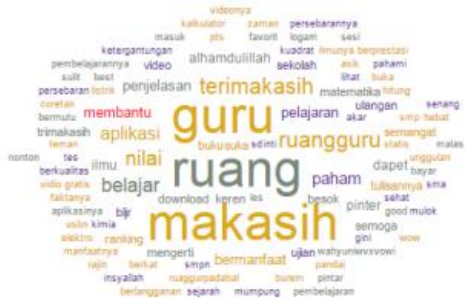

Gambar 13. Word cloud jenjang pendidikan SMP

Di jenjang SMP, topik yang paling banyak dibicarakan adalah mengenai; terimakasih, belajar, sekolah, nilai, dll, dan kata yang paling banyak muncul adalah kata; terimakasih, nilai, belajar, aplikasi, paham, pelajaran, dll.

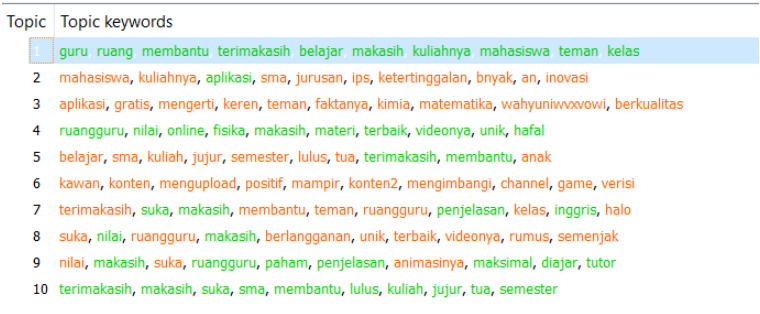

Gambar 14. Topic Modelling jenjang pendidikan SD

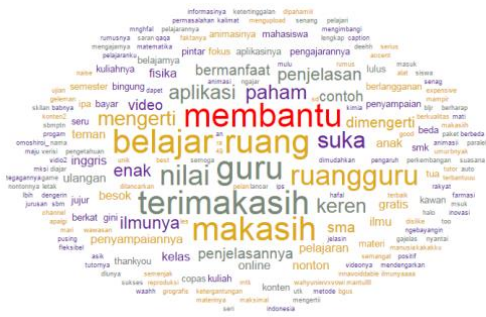

Gambar 15. Word cloud jenjang pendidikan $S D$

Di jenjang SD, topik yang paling banyak dibicarakan adalah mengenai; membantu, terimakasih, belajar, kelas, dll, dan kata yang paling banyak muncul adalah kata; terimakasih, membantu, belajar, nilai, suka, paham, aplikasi, dll.

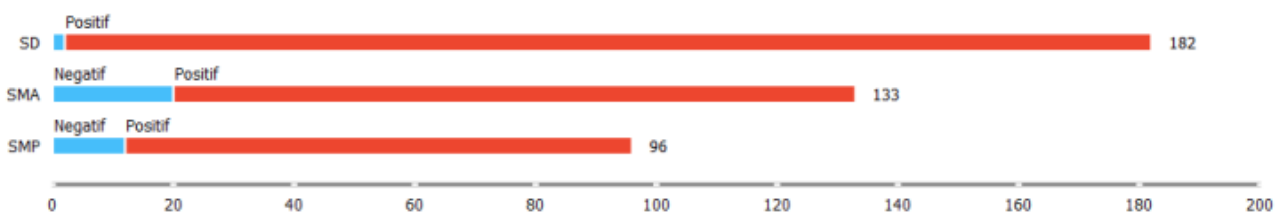

Gambar 10. Plot tanggapan pelanggan berdasarkan jenjang pendidikan

Setelah data di analisis menggunakan Orange, dapat dilihat dari data plot telah terbentuk 3 klasifikasi yang berdasarkan jenjang pendidikan, yaitu kelas SD, kelas SMP, dan kelas SMA.

Analisis Grafik :

a) Di kelas SD, yang memberi komentar dengan sentimen positif sebesar (180 orang), dan komentar dengan sentimen negatif ( 2 orang).

b) Di kelas SMP, yang memberi komentar dengan sentimen positif sebesar (84 orang), dan komentar dengan sentimen negatif (12 orang). 
c) Di kelas SMA, yang memberi komentar dengan sentimen positif sebesar (113 orang), dan komentar dengan sentimen negatif (20 orang).

\section{SIMPULAN}

Dari hasil pembahasan di atas, respon di komentar YouTube terhadap fitur ruangbelajar dari Ruangguru kebanyakan pengguna memberikan respon dengan sentimen positif, ini berarti para penggunanya merasa puas dengan fitur ruangbelajar yang diberikan oleh Ruangguru, dimana pengguna yang memberikan respon dengan sentimen positif membicarakan tentang bagaimana fitur ruangbelajar dapat membuat mereka mengerti lebih mudah tentang suatu pelajaran dan juga membantu mereka dalam mendapat nilai yang lebih bagus dalam pelajaran, videonya yang menarik, dll. Selain itu, meskipun Ruangguru mendapatkan banyak respon dengan sentimen positif, masih ada pengguna yang memberikan respon sentimen negatif seperti penjelasannya yang terlalu lama dan banyak menggunakan kata-kata yang tidak perlu, tulisan di video kurang jelas atau terlalu kecil untuk beberapa orang, dll. Karena itu, Ruangguru perlu meningkatkan lagi fitur ruangbelajarnya agar dapat memenuhi kepuasan dari pengguna fitur tersebut.

Saran dari kami Ruangguru dapat meningkatkan fitur ruangbelajarnya dengan cara memperbesar tulisan yang ada di video mereka, menggunakan diksi yang sesuai dengan jenjang pendidikannya, meningkatkan kualitas videonya, memberikan penjelasan dengan lebih singkat danj jelas, dan juga lebih banyak memberikan contoh soal agar lebih mudah dimengerti.

\section{DAFTAR PUSTAKA}

[1] Dave, Lawrence, \& Pennock., "Mining the Peanut Gallery: Opinion Extraction and Semantic Classification of Product Reviews", WWW 2003, Computer Science, 775152, pp 519-528, Oktober 2003.

[2] Akshi Kumar and Teeja Mary Sebastian., "Sentiment Classification of Tweets with Non-Language Features", Prodecia Computer Science, Vol. 143, pp. 426433, Oktober 2018.

[3] Schneider Friedrich, "Shadow economies around the world: what do we really know?" European Journal of Political Economy, Vol. 21, pp. 598-642, July 2006.

[4] Philip Kotler, "Manajemen Pemasaran”, Jilid 2, Prenhallindo, Jakarta, 2002.

[5] D. M. Blei, "Latent Dirichlet Allocation", Machine Learning Research 3, 2003.

[6] D. M. Blei, "Probabilistic Topic Model", vol. 55, 2012.

[7] Andrew E. Sikula, "Manajemen Sumber Daya Manusia", Erlangga, Bandung, 2000.

[8] UU RI No. 20, “Tentang Sistem Pendidikan Nasional”, Pasal 1, 2003.

[9] Ruangguru, "Tentang Ruangguru", 2019. [Online], Tersedia: https://ruang guru.com/general/about,.

[10] Rizal, Adam, "Pengguna Tembus 11 Jutaan, Inilah 3 Keunggulan Aplikasi Zenius App", 2019. [Online], Tersedia: https://infokomputer. grid.id/read/ 121788970/pengguna-tembus-11-jutaan-inilah-3-keunggulan-aplikasizenius-app?page=all,. 
Jurnal Sains Komputer \& Informatika (J-SAKTI)

Volume 4 Nomor 1 Maret 2020, pp. 66-76

ISSN: 2548-9771/EISSN: 2549-7200

http://tunasbangsa.ac.id/ejurnal/index.php/jsakti

[11] Simamora, Novita Sari, "Pengguna Quipper Indonesia Capai 6 Juta Pelajar", 2019. [Online], Tersedia: https://teknologi.bisnis.com/read/2019 0715/280/1124052/pengguna-quipper-indonesia-capai-6-juta-pelajar,.

[12] Nabila, Marsya, "Miliki 15 Juta Pengguna, Ruangguru Siapkan Debut Ekspansi Ke Luar Negeri", 2019. [Online], Tersedia: https://dailysocial.id /post/ruangguru-siapkan-ekspansi-ke-luar-negeri,. 